\title{
Evolución el añublo del arroz en dos condiciones de fertilidad nitrogenada
}

\author{
María Pinciroli, Cristina A. Cordo ${ }^{2}$, Rodolfo Bezus ${ }^{1}$, Alfonso A.Vidal ${ }^{1}$, Martín Delucis ${ }^{3}$.
}

${ }^{1}$ Programa Arroz; e-mail: mpinciroli @ ceres.agro.unlp.edu.ar. ${ }^{2}$ CIDEFI Cátedra de Fitopatología, UNLP-CIC-CONICET; ${ }^{3}$ Cátedra de Cálculo Estadístico y Biometría. Facultad Ciencias Agrarias y Forestales, UNLP. 66 y 167 cc.31-1900. La Plata, Buenos Aires, Argentina.

Data de chegada: 27/08/2004. Aceito para publicação em: 15/09/2005.

\section{RESUMEN}

Pinciroli, M.; Cordo, M.C.; Bezus, R.; Vidal, A.A.; Delucis, M. Evolución del añublo del arroz en dos condiciones de fertilidad nitrogenada. Summa Phytopathologica. v.32, n.3, p.280-282, 2006.

Con el objetivo de evaluar la evolución de la infección producida por Pyricularia oryzae (cooke) Sacc, en la hoja y en la panícula, fueron seleccionados tres genotipos de arroz (Oryza sativa). Los genotipos: El Paso 144 (EP), Don Ignacio (DI) y H 316-1-2-1-1 (H 316) fueron sembrados en condiciones de campo, en la Estación Experimental La Plata, y en dos condiciones de disponibilidad de nitrógeno (testigo o sin nitrógeno y $150 \mathrm{~kg} \mathrm{~N} \mathrm{ha}^{-1} \mathrm{en}$ forma de urea). El hongo fue inoculado en la tercera hoja, con una mezcla de razas, a una concentración de $1,2 \times 10^{5}$ fragmentos de hifa $/ \mathrm{ml}$, incubándose durante 48 horas en cámara húmeda. Fueron evaluados la severidad y tipo de mancha en la hoja y la severidad e incidencia en la panícula. Se realizó el ANOVA, y las diferencias estadísticas fueron analizadas a través del test Tukey $(\mathrm{p}<0,05)$. Fueron aplicados modelos Log-lineares para datos no paramétricos. No se observó interacción entre genotipo y fertilización, en las hojas, en los estadios de primer perfilo (M) y diferenciación (D). La fertilización aumentó la severidad en las hojas. El coeficiente de correlación entre el tipo de mancha y el porcentaje de severidad en la hoja fue elevado. Fue observada interacción entre genotipo y fertilización en los valores de severidad en la panícula, los mismos que disminuyeron con la fertilización en los genotipos EP y DI, pero no presentaron diferencias en H 316.

Palabras clave adicionales: añublo, nitrógeno, Oryza sativa.

\section{ABSTRACT}

Pinciroli, M.; Cordo, M.C.; Bezus, R.; Vidal, A.A.; Delucis, M. Development of rice blast under two nitrogen availability conditions. Summa Phytopathologica. v.32, n.3, p.280-282, 2006.

Three rice genotypes (Oryza sativa) were chosen, among some commercial cultivars and advanced lines, in order to evaluate the influence of nitrogen levels on leaf and panicle blast infection caused by Pyricularia grisea (Cooke) Sacc. Three genotypes El Paso 144 (EP), Don Ignacio (DI) and H 316-1-2-1-1 (H 316) under two nitrogen levels (without nitrogen and $150 \mathrm{~kg} \mathrm{~N} \mathrm{ha}^{-1}$ as urea). Plants were inoculated on third leaf with a mixture of several insolates at a concentration of $1,2 \times 10^{5}$ hyphae fragments $/ \mathrm{ml}$ and was incubated during 48 hours in a wet room. Leaf blast severity and lesion type, and panicle blast severity an incidence were evaluated. Data were analyzed by using ANOVA, and differences in means were compared by Tukey $(\mathrm{p}<0,05)$. Log-lineal models were applied with nonparametrical data. Genotype fertilization interaction in relation to leaf blast was not observed, at first shoot (M) and boot stages (D). Nitrogen fertilization increased leaf blast severity. Correlation between lesion type and percentage of leaf blast severity was high. Panicle blast severity was significantly reduced by $\mathrm{N}$ fertilization in genotypes EP and but not in $\mathrm{H} 316$.

Additional keywords: blast disease, nitrogen, Oryza sativa.

\section{RESUMO}

Pinciroli, M.; Cordo, C.A.; Bezus, R.; Vidal, A.A.; Delucis, M. Evolução do brusone do arroz em duas condições de adubação nitrogenada. Summa Phytopathologica. v.32, n.3, p.280-282, 2006

Com o objetivo de avaliar a evolução da infecção produzida por Pyricularia oryzae (Cooke) Sacc, em folha e em panícula, foram selecionados três genótipos de arroz (Oryza sativa). Os genótipos: El Paso 144 (EP), Don Ignacio (DI) e H 316-1-2-1-1 (H 316) foram semeados em condições de campo, na Estação Experimental La Plata, e em duas condições de disponibilidade de nitrogênio (testemunha: sem nitrogênio e $150 \mathrm{~kg} \mathrm{~N}$ ha-1 $^{-1}$ na forma de uréia). O fungo foi inoculado na terceira folha, com uma mistura de raças, e uma concentração de 1,2 x $10^{5}$ fragmentos de hifa/ml, incubando-se durante 48 hs em câmara úmida. Foram avaliadas a severidade e tipo de mancha na folha e severidade e incidência na panícula. Foi realizado ANOVA, e as diferenças estatística foram analizadas pelo teste Tukey $(\mathrm{p}<0,05)$. Foram aplicados modelos Log-lineais para dados não paramétricos. Não foram registradas interacões genótipo/abudação nas observações em folha, nos estadios de primeiro perefilho (M) e difenciação (D), a abudação aumentou a severidade. O coeficiente de correlação entre o tipo de mancha e porcentagem de severidade em folha foram elevadas. Foi observou interação entre genótipo/abudação nos valores de severidade em panícula. Os mesmos diminuíram com a abudação em EP e DI, mas não apresentan diferenças em H 316.

Palavras-chave adicionais: brusone, nitrogênio, Oryza sativa. 
El añublo del arroz producido por Pyricularia grisea (Cooke) Sacc. Syn. P. oryzae Cav., es considerada mundialmente la enfermedad de mayor importancia económica. El patógeno infecta el arroz causando manchas necróticas en la hoja, en el cuello y raquis de la panoja y en el grano (1). Prácticas como manejo del agua, densidad de siembra, utilización de genotipos resistentes y fertilidad del suelo, son efectivas para su control. Las dosis de nitrógeno y el momento de aplicación influyen en la ocurrencia y severidad del añublo, así como en el tipo y tamaño de la lesión.

El objetivo fue evaluar la infección producida por Pyricularia grisea en hoja y en panoja, en distintos genotipos de arroz en dos condiciones de fertilidad nitrogenada.

Se sembró un ensayo en campo en La Plata ( $57^{\circ} 57^{\prime} \mathrm{W}, 34^{\circ} 54^{\prime} \mathrm{S}$, $15 \mathrm{~m} \mathrm{snm}$.). El suelo correspondió a un Argiudol típico con 3,5\% de $\mathrm{MO}, 0,146 \%$ de $\mathrm{N}$ total, $10 \mathrm{ppm}$ de $\mathrm{NO}_{3}$ y $21 \mathrm{ppm}$ de P. El diseño fue en bloques completos al azar, con tres repeticiones; los genotipos fueron: El Paso 144 (EP), Don Ignacio FCA y F (DI) y H 316-1-2-1-1 (H 316), los cuales se diferencian en la longitud del ciclo, la capacidad de absorción del nitrógeno y la partición del mismo en las estructuras vegetales. Los tratamientos fueron: 1- testigo y 2 - suplementado con $150 \mathrm{~kg} \mathrm{~N}$ $\mathrm{ha}^{-1}$ en forma de urea granular: mitad de la dosis en primer macollo y el resto en antesis. La infección se generó por inoculación artificial. Considerando el tipo de resistencia (horizontal) se utilizó una mezcla de 10 aislamientos para posibilitar a todos los genotipos hospedantes de expresar su resistencia. El inóculo consistió en fragmentos de micelio suspendidos en agua destilada $\left(1,2 \times 10^{5}\right.$ trozos de hifa/ml), adicionando Tween 20 al $0,02 \%$. Se aplicó, en tercera hoja con pulverizador mochila hasta escurrimiento y se mantuvo 72 hs. en cámara húmeda cubierta con polietileno transparente y mediasombra. Se evaluó severidad a partir de 30 plantas y 30 panojas por parcela e incidencia a partir de $0,90 \mathrm{~m}$ lineales de cultivo (entre 90 y 120 panojas) por parcela en 3 etapas: primer macollo, (M), diferenciación (D), embuchado (E) y grano céreo (GC). Se determinó severidad (porcentaje de área foliar (3) y de panoja (1) afectada (AFA y APA respectivamente)) e incidencia, como porcentaje de cuellos afectados (2). En hoja se determinó, además, el tipo de mancha (T) (3). Se realizó el análisis de la varianza ANOVA y las medias se compararon por el test de Tukey $(p<0,05)$. Los datos fueron previamente transformados “ $(x+1 / 2)$. En $D$, se realizó una correlación de Spearman con los valores de AFA y T, agrupados según T, genotipo $(\mathrm{G})$ y fertilidad $(\mathrm{F})$. Para su análisis se utilizaron los siguientes modelos $\log$-lineales: Modelo G, F, T: todas la variables son mutuamente independientes; Modelo GF, T: solo se considera la asociación GF. T es independiente; Modelo FT, G: solo se considera la asociación FT. G es independiente; Modelo GT, F: solo se considera la asociación GT. F es independiente; Modelo GF, FT: G es independiente de T para cada valor de F; Modelo FT, GT: F es independiente de G para cada valor de T; Modelo GF, FT, GT: asociación dos a dos entre todas las variables; Modelo saturado GFT: se considera la asociación de las tres variables.

No se observó interacción genotipo por fertilidad en severidad en hoja e incidencia (Tabla 1). En M y D se observó un incremento de la severidad con la fertilización. El mayor contenido de nitrógeno en las estructuras del huésped pudo haber favorecido procesos metabólicos enzimáticos aumentando la severidad de la enfermedad. Tanto en E como en GC la fertilización no ejerció influencia sobre la infección en hoja. Los tres genotipos alcanzaron un máximo de infección en el pasaje al estado reproductivo (D). Los valores mas elevados los alcanzó $\mathrm{EP}$, dado que es la variedad más difundida en la zona, podría inferirse la presencia mayoritaria de razas fisiológicas virulentas, específicas para este germoplasma en la mezcla de aislamientos. La fertilización no incrementó la incidencia de la enfermedad en los materiales estudiados, tendencia similar fue observada por Long (2). La correlación entre T y severidad observado en hoja, en las etapas M D y E, fue positiva y altamente significativa $(\mathrm{r}=0,7990 ; \mathrm{p}<0,01)$. Del análisis de los modelos log-lineales se observó que cuando se incluyó la asociación GF dentro de cada modelo, los valores de p-value disminuyeron, lo que indicó un peor ajuste del modelo. Esto corroboró la independencia entre estas dos variables observada en los resultados del ANOVA. Para la selección del modelo, se optó por no considerar aquellos

Tabla 1: Severidad, expresada como media de los porcentajes de área foliar afectada e incidencia expresada como media de los porcentajes de panoja afectada por Pyricularia grisea en genotipos de arroz para las distintas etapas fenológicas y condiciones de fertilidad nitrogenada. La Plata, 2003.

\begin{tabular}{|c|c|c|c|c|c|}
\hline \multirow[t]{2}{*}{ Fuentes de variación } & \multicolumn{4}{|c|}{ Severidad } & \multirow{2}{*}{$\begin{array}{c}\text { Incidencia } \\
\text { GC }\end{array}$} \\
\hline & $\mathbf{M}$ & D & $\mathbf{E}$ & GC & \\
\hline \multicolumn{6}{|l|}{ Dosis de fertilizante } \\
\hline \multicolumn{6}{|l|}{ kg N ha' ${ }^{-1}$ DF) } \\
\hline 0 & $1,01 \mathrm{a}$ & $2,80 \mathrm{a}$ & $1,06 \mathrm{a}$ & $1,22 \mathrm{a}$ & 10,09 a \\
\hline 150 & $4,66 \mathrm{~b}$ & $10,23 \mathrm{~b}$ & $1,11 \mathrm{a}$ & $1,38 \mathrm{a}$ & $11,82 \mathrm{a}$ \\
\hline \multicolumn{6}{|l|}{ Genotipos (G) } \\
\hline EP & $2,76 \mathrm{a}$ & $11,66 \mathrm{~b}$ & $1,2 \mathrm{ab}$ & $1,10 \mathrm{a}$ & $5,97 \mathrm{a}$ \\
\hline DI & $2,66 \mathrm{a}$ & $4,70 \mathrm{a}$ & $0,30 \mathrm{a}$ & $1,41 \mathrm{a}$ & $15,86 \mathrm{~b}$ \\
\hline \multirow[t]{2}{*}{ H 316} & $3,16 \quad b$ & $3,18 \mathrm{a}$ & $1,75 \mathrm{~b}$ & $1,37 \mathrm{a}$ & $11,03 \mathrm{~b}$ \\
\hline & \multicolumn{5}{|c|}{ Significância de F } \\
\hline DF & $*$ & $* *$ & $\mathrm{n} / \mathrm{s}$ & $\mathrm{n} / \mathrm{s}$ & $\mathrm{n} / \mathrm{s}$ \\
\hline G & $*$ & $* *$ & $*$ & $\mathrm{n} / \mathrm{s}$ & $* *$ \\
\hline DF x G & $\mathrm{n} / \mathrm{s}$ & $\mathrm{n} / \mathrm{s}$ & $\mathrm{n} / \mathrm{s}$ & $\mathrm{n} / \mathrm{s}$ & $\mathrm{n} / \mathrm{s}$ \\
\hline
\end{tabular}

Referencias: $\mathrm{M}=$ primer macollo; $\mathrm{D}=$ diferenciación de la panoja; $\mathrm{E}=$ embuchado; $\mathrm{GC}=$ maduración (grano céreo), $\mathrm{n} / \mathrm{s}$ no significativo; $*$ y** significativo al $5 \%$ y $1 \%$ respectivamente (test de $\mathrm{F}$ ).

Medias seguidas por letras iguales dentro de cada columna, para cada factor no se diferencian entre sí por el test de Tukey $(\mathrm{p}<0,05)$. 


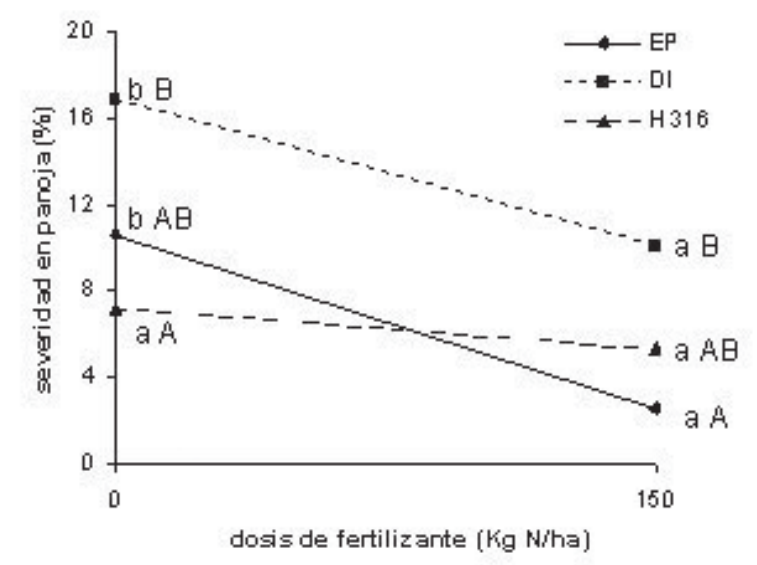

Figura 1: Análisis de las interacciones fertilidad nitrogenada $\mathrm{x}$ genotipos para la variable porcentaje de severidad en panoja. La Plata, 2003. Medias seguidas por letras iguales minúsculas horizontales y mayúsculas verticales no difieren entre sí para el test de Tukey $(\mathrm{p}<0,05)$.

que contenían la asociación GF. De los modelos restantes, los dos que presentaron diferencias no significativas ( $p$-value $>0,05$ ) frente al modelo saturado, fueron: FT, G y FT, GT. Para contrastar estos 2 últimos, se calculó la diferencia entre los valores de coeficiente de verosimilitud $\left(\mathrm{G}^{2}\right)$. Dicho análisis mostró diferencias no significativas por lo que se decidió tomar el modelo FT, G dada su simplicidad.

En panoja se observó interacción genotipo x fertilidad nitrogenada. EP y DI presentaron un porcentaje de severidad menor, mientras H 316 no presentó diferencias (Figura 1). Este comportamiento coincidió con los resultados de Roumen (4), quien explicó una posible forma de resistencia de tipo "escape". La infección en panoja se produce en un tiempo breve y posiblemente los genotipos fertilizados que florecieron seis días después, hayan escapado a la enfermedad, por las condiciones ambientales diferentes. H 316 no presentó diferencias en la fecha de panojamiento. Por otro lado, con la fertilización EP y DI, incrementaron sus rendimientos y biomasa (datos no mostrados), posiblemente esto haya disminuído el contenido de nitrógeno de los tejidos al distribuirse en mayor número de estructuras reproductivas (5).

Del análisis de este trabajo se deduce que la fertilización nitrogenada influye de distinta manera sobre la susceptibilidad a $P$. grisea en hoja y en panoja. En hoja todos los genotipos incrementaron la infección con la fertilización. En el estado reproductivo, en cambio, resulta de gran importancia conocer el material genético ya que se observó que la susceptibilidad de los genotipos al patógeno es diferencial, especialmente considerando que según varios autores (2) la severidad en panoja influye en mayor medida sobre la pérdida de rendimientos.

\section{REFERENCIASBIBLIOGRÁFICAS}

1. Filippi, M.C.; Prabhu, A.S. Effect of leaf blast control by Pyroquilon seed treatment on panicle blast progress and grain yield. Fitopatologia Brasileira, Goiânia, v.22, p.164-170, 1997.

2. Long, D. H. Effect of nitrogen fertilization on disease progress of rice blast on susceptible and resistant cultivars. Plant Disease, Arkansas, v.84, n. 4, p.403-409, 2000.

3. Notteghem, J.C. Cooperative experiment on horizontal resistance to rice blast. In: International Rice Research Institute. Blast and upland rice: report and recommendation from the meeting for international collaboration in upland rice improvement. Los Baños, 1981. p.43-51.

4. Roumen, E.C. Partial resistance to neck blast influenced by stage of panicle development and rice genotype. Euphytica, Netherlans, v. 64, p.173-182, 1993.

5. Souza, S.R.; Stark, L.M.; Fernandes, M.S. Foliar spraying of rice with nitrogen: Effect on protein levels, protein fractions and grain weight. Journal of Plant Nutrition, Seropédica, v.22, n.3, p.579588, 1999. 